\title{
Processos projetuais em design gráfico e editorial: um estudo de caso da Revista Galileu
}

\author{
Design processes in graphic and editorial design: the Galileu Magazine \\ case study
}

LAGO, Lílian

Universidade Estadual Paulista - UNESP I lago.lilian@gmail.com

BATISTA, Murilo André Pessoa

Universidade Estadual de Londrina - UEL I murilopessoa86@gmail.com

DOMICIANO, Cassia Leticia Carrara

Universidade Estadual Paulista - UNESP I carrara@faac.unesp.br

\begin{abstract}
Resumo
A complexidade do cenário atual exige processos e métodos flexíveis e adaptáveis ao contexto, especialmente no design gráfico e editorial, área tão influente na cultura visual. Os procedimentos metodológicos deste trabalho consistem em uma revisão de literatura sobre design e metodologia projetual, o estudo de três obras sobre fundamentos e processos em design gráfico e o estudo de caso do novo projeto gráfico da revista Galileu. Acompanhando a revista por dez edições foi possível esboçar seu processo de redesign e seu processo projetual contínuo, que acontece a cada edição. Desta forma, pode-se considerar o novo projeto da revista Galileu um exemplo de trabalho contemporâneo que reúne design, comunicação e artes visuais na materialização de um produto que discute a ciência em toda sua amplitude a fim de informar da melhor forma seu leitor.
\end{abstract}

Palavras-chave: Design editorial. Projeto gráfico. Processos em design gráfico. Métodos de design gráfico.

\section{Abstract}

The complexity of the current social scenario requires processes and methods that are more flexible and adaptable to the context, especially in graphic and editorial design, for they are very influential of the visual culture. The methodological procedures of this study consist of a literature review on design and project methodology, the study of three books about fundamentals and processes in graphic design, and the case study of the Galileu magazine's new graphic project. By following the magazine for ten editions, it was possible to understand its graphic redesign and its continuous design process, which spans across every new edition. Thus, we conclude that Galileu magazine's new project is an example of contemporary work that brings together design, communication and visual arts in the materialization of a product that fully discusses science in order to provide comprehensive information to the reader.

Keywords: Editorial design. Graphic design. Graphic design processes. Graphic design methods. 


\section{INTRODUC̣ÃO}

A necessidade de se construir uma metodologia projetual de design teve origem ainda no ano de 1960, devido, principalmente, à complexidade dos problemas a serem solucionados. O cenário atual envolve diversidades, multiplicidades, hibridizações, transversalidades, entre outros fenômenos que exigem processos e métodos flexíveis e adaptáveis ao contexto. O design gráfico e o design editorial, em particular, evidenciam uma preocupação mais recente em apresentar processos, se comparados ao design industrial ou ao design de produto. Por isso, a demanda pela pesquisa sobre processos e métodos na área ainda é grande.

Para delinear as características dos processos de desenvolvimento de projetos em design gráfico e editorial, foram selecionadas três referências Fuentes (2006), Samara (2011) e Dabner (2014) - que servirão de suporte para a análise do processo de desenvolvimento do projeto gráfico e editorial da Revista Galileu, implantado no final de 2015. O objetivo é entender e identificar características contemporâneas no projeto e no processo de construção do design da revista. A escolha destas obras se deu por serem literaturas reconhecidas na área e a escolha da revista, por ter sido destaque em um ano de retração no mercado editorial brasileiro.

\section{DESIGN E METODOLOGIA PROJETUAL}

Alexander (1964 apud BÜRDEK, 2006), um dos fundadores da metodologia em design, cita quatro argumentos para a existência de uma metodologia de projeto: a complexidade dos projetos, que exigiam mais do que intuição para sua solução; o volume de informações a serem coletadas e manipuladas; o volume de problemas dentro do projeto; a crescente particularidade de cada projeto, que tornava cada vez mais raro poder se valer de experiências anteriores.

Para van der Linden e Lacerda (2012), o conceito de complexidade sempre esteve presente no discurso projetual, mas de forma quantitativa, como em números de componentes do problema. No cenário atual, a complexidade vai além de aspectos quantitativos e até mesmo qualitativos, "a noção de complexidade envolve a convivência com paradoxos, como a ordem e a desordem atuando de forma autogenerativa" (VAN DER LINDEN; LACERDA, 2012, p. 88).

De acordo com Bonsiepe (2012), a metodologia de projeto da década de 1960 não enfatizava alguns fatores imprescindíveis nos dias de hoje, tais com o uso de recursos não renováveis, poluição, consumo de energia durante 
o ciclo de vida do produto e atenção às minorias populacionais - como idosos e portadores de necessidades especiais. Para o autor, um movimento de design alternativo se faz presente atualmente, todavia questiona-se se este é consistente a ponto de estabelecer uma metodologia projetual alternativa, capaz de produzir um design mais equitativo, participativo, menos poluente e consumidor de energia e recursos ou produzido em pequenas comunidades ou cooperativas. Dessa forma, segundo o autor, uma metodologia projetual alternativa já está sendo praticada, apesar de ainda não ter sido formalizada no nível conceitual da metodologia clássica.

Moura (2011) afirma que o design contemporâneo rompe as fronteiras e reintegra diversas áreas, desde as mais próximas - a arte, a arquitetura, a engenharia, a moda, a sustentabilidade, a ergonomia - até as mais distantes, como a medicina, a física e a biotecnologia. É possível perceber a busca por um pensamento projetual mais amplo e consistente. Nota-se também que o design contemporâneo atua de forma coletiva, como em grupos criativos e desenvolvedores. Estas novas formas de organização confirmam a presença da ação interdisciplinar e as possibilidades transdisciplinares na ação projetual. Assim, "se o design estabelece intensas relações com as questões culturais, sociopolíticas e econômicas, cabe a nós verificar os aspectos da contemporaneidade para refletir sobre as possibilidades de novas formas de métodos e metodologias projetuais" (MOURA, 2011, p. 257).

Moraes (2008) explica que a complexidade pela qual se caracteriza o momento atual exige que as mudanças sejam vistas e compreendidas - tarefa nem sempre simples - para que produtos tangíveis e intangíveis consigam interagir com seus usuários por meio de suas interfaces, numa relação sempre dinâmica. Na era do conhecimento, o usuário está ciente de seus direitos e desejos enquanto cidadão e consumidor. A disputa por mercado faz com que as características e benefícios de cada produto ofertado sejam intensamente comunicados ao usuário. Conhecê-lo se torna pré-requisito para projetar para ele. Ademais, de acordo com o autor, pesquisas mercadológicas predominantemente estatísticas antes eram suficientes para o mercado. Hoje, há a necessidade de interpretações qualitativas. O projeto adequado à complexidade do cenário demanda flexibilidade, deve estar "aberto a novos eventos, prevendo a necessidade de mudanças e incorporando o usuário como participante ativo da solução que será proposta" (KRUCKEN, 2009, p. 45).

Reyes (2011) acredita que o projeto de design é um processo complexo e deve ser entendido como um sistema aberto, que pode ser revisado a qualquer momento por meio da construção de diferentes cenários. Para Gomez (2004, p. 34), "o profissional da contemporaneidade não pode mais seguir rumos lineares. Precisa incorporar distintas áreas de conhecimento para contextualizar a sua atuação, tornando-a mais abrangente". 
De acordo com Plunkett (2013), o design, especialmente o design gráfico, costuma ser concebido como o produto final, o resultado visível, palpável de um processo. No entanto, o autor considera que este processo tem maior importância do que o resultado final. Desta forma, o designer deve estar mais atento às questões do conteúdo do que às relacionadas à forma para contribuir significativamente com seu projeto.

Mas como reposicionar o fazer projetual em meio a essas mudanças e ao questionamento de paradigmas? Sem dúvidas ainda há muito a entender sobre esse processo.

Joan Costa, no prólogo de Fuentes (2006), afirma que em design gráfico "temos muita tecnologia, pouca metodologia e nada de filosofia". Bonsiepe (2011) também constata que o design gráfico foi pouco pesquisado. Todavia, o designer é "produtor e criador de sistemas funcionais, comunicacionais e estéticos, os quais de alguma maneira irão influir para a construção da cultura visual, e por sua vez, da estrutura da sociedade" (PORTUGAL, 2013, p. 35).

Esta responsabilidade atribuída ao designer ressalta a importância da compreensão e prática de processos e métodos de design gráfico. Busca-se tal compreensão a seguir, por meio de uma seleção de três obras relevantes entre as publicações na área.

\section{PROCESSOS PROJETUAIS EM DESIGN GRÁFICO E EDITORIAL}

\subsection{Processo Projetual de Fuentes (2006)}

Fuentes (2006, p. 31) descreve o processo de design gráfico unindo teoria e prática e apresenta o que ele, em seus anos de carreira como designer gráfico e professor, considera essencial na atividade do designer. O autor não defende a imposição de um processo, mas sim o estímulo para que cada designer busque seu processo, métodos, prática de trabalho ou "linguagem própria de design". Juntamente com a descrição do processo, o autor disserta sobre fundamentos visuais e aspectos técnicos e produtivos do design gráfico.

Para Fuentes (2006), o ponto de partida do processo de design é a definição da necessidade do cliente, o reconhecimento das razões desencadeadoras daquela demanda que se tornou projeto. $O$ formato mais comum desta investigação é o briefing. Em seguida, está a análise desta necessidade, momento em que são coletadas informações relacionadas direta ou indiretamente com o projeto e que irão afetá-lo; dentre elas inserem-se: condições orçamentárias, prazos, planejamentos de marketing, implicações ético-morais e codificações culturais. Feita a análise, dá-se início à pesquisa que irá completar o dossiê de informações necessárias à concepção do projeto. 
Devem ser pesquisados: concorrência local, referenciais, dados históricos próprios e relacionados, público-alvo, entre outros temas pertinentes, a depender do projeto. Esta primeira fase tem como objetivo coletar, avaliar e organizar elementos e informações que estavam até então desordenados.

A segunda fase do processo é a concepção, quando os dados coletados são escolhidos para serem utilizados juntamente com a experiência de trabalho do designer, dando sequência ao processo e forma ao projeto, um momento de síntese e decisão. Também é a hora da expressão gráfica, da produção do layout que irá comunicar a mensagem desejada.

A terceira fase é a concretização. Os elementos e informações coletados e selecionados já produziram conceitos expressados graficamente e agora, com a ajuda das ferramentas analógicas e digitais, serão refinados em busca de um bom resultado. São abordados: estrutura, escala, tipografia, cor, suporte, imagens, métodos de pré-impressão, impressão, acabamento e encadernação. Estes conteúdos são apresentados de forma didática, unindo teoria e prática profissional.

De forma paralela, atividades internas coexistem no processo de design. Uma delas é a visualização crítica. Ela deve estar presente em cada etapa do processo de desenvolvimento, agindo a fim de se evitarem erros e prejuízos no processo. Na visualização crítica, a bagagem de aprendizados do designer é utilizada, tanto quanto novos aprendizados são adquiridos. Outra atividade paralela é o controle no processo gráfico. Todas as etapas de produção devem ser acompanhadas - revisadas e validadas -, incluindo a aprovação por parte do cliente em etapas como a pré-impressão.

O conhecimento do cliente, assim como o autoconhecimento do designer, devem permear todo o processo. "O cliente nem sempre tem razão. Nem o designer" (FUENTES, 2006, p. 117). O autor preza por um bom relacionamento colaborativo entre cliente e designer a fim de conseguir a melhor solução de comunicação. O designer, por sua vez, deve ser um curioso nato. Não deve haver divisão entre o racional e o intuitivo ou entre o prático e o criativo em seu trabalho. A atividade de design deve ser sensível ao contexto, encontrar uma linguagem adequada para cada projeto (Figura 1). 
Figura 1 - Processo de design de Fuentes (2006).

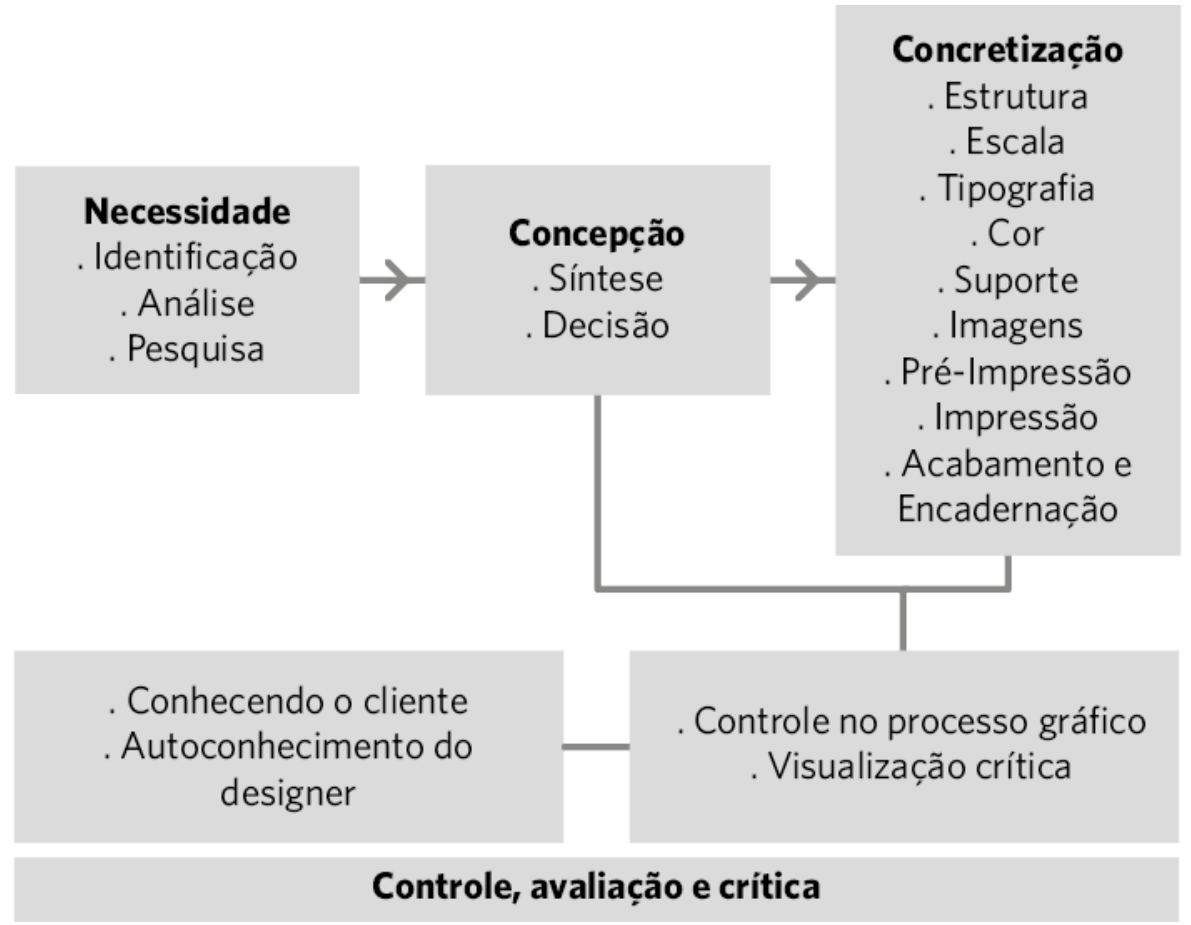

Fonte: os autores, baseados em Fuentes (2006).

\subsection{Processo Projetual de Samara (2011)}

Samara (2011) traz uma abordagem mais metódica do que a de Fuentes (2006) e voltada especificamente para o design editorial. Sua obra apresenta duas grandes partes: a primeira sobre teoria e prática do design editorial e a segunda sobre estudos de caso. Assim como no texto de Fuentes (2006), a redação de Samara (2011) mescla fundamentos visuais com aspectos técnicos e produtivos do design editorial.

A partir da compreensão da primeira parte do livro, é possível visualizar o processo de design do autor, que pode ser divido em três fases. A primeira fase tem início com o exame detalhado do conteúdo a ser trabalhado na publicação. É comum que o desenvolvedor do conteúdo já tenha em mãos textos e, talvez, até imagens. Se o formato da publicação ainda não foi definido pelo editor, a ajuda do designer é bem-vinda. Em ambas as situações, a tarefa do designer é, a partir do exame do conteúdo, começar a pensar na forma visual da publicação, levando em conta as mensagens que ela deverá expressar. Portanto, antes de começar a projetar, deve-se compreender a temática, o contexto cultural e o público.

Para o autor, toda a comunicação visual pode ter três funções de conceito: a) a função primária, que traduz os aspectos intrínsecos do produto, onde o conteúdo é seu próprio conceito; b) a secundária, que se relaciona com 
um público específico; c) a terciária, que envolve o branding e o posicionamento - que filtram mais uma vez a interpretação da mensagem primária.

Uma publicação pode dar ênfase em qualquer uma destas funções, basta ter ciência sobre qual delas trará melhor resultado frente à percepção do público: a primária, que apresenta transparência ao leitor; a secundária, que aproxima o público da publicação; ou a terciária, que promove apelo ou ação específica do leitor.

Após o exercício de compreensão do conteúdo e conceituação da publicação, é preciso organizá-lo: definir seções e a sequência da informação. O conteúdo deve ser decomposto para ser organizado, seja por tipo, partes para o todo, por complexidade, por cronologia ou por relevância. Uma publicação não costuma ser feita apenas com textos escritos. Imagens, cores e tipografias servem como suportes visuais ao conteúdo textual e acabam se tornando conteúdo integrante da publicação. Publicações de caráter documental demandam imagens objetivas, representacionais, que enfatizarão a função primária do conceito. Já publicações que fazem uso de imagens mais abstratas comunicam de forma mais subjetiva e interpretativa, aproximando a comunicação das funções conceituais secundária ou terciária.

A segunda fase trata dos aspectos relacionados à leitura da publicação. Outros autores da área, ou mesmo docentes, costumam propor a construção prática do projeto do macro ao micro, do formato e do grid à tipografia e seus detalhes. No entanto, Samara (2011) propõe o inverso, que seja de dentro para fora, que primeiramente seja estudada a tipografia, depois a composição do texto e a hierarquia informacional dentro da publicação. Esta lógica alcança até a terceira fase com formatos, grid, sequência e cadência dos conteúdos e, por fim, o exterior da publicação. A escolha das tipografias deve, primeiramente, atender às necessidades de leitura e compreensão da mensagem. A informação tratada poderá ser complexa a ponto de exigir diversos níveis hierárquicos, como títulos e subtítulos, e a tipografia tem importante papel na eficácia da localização e percepção destes níveis. Por fim, o designer deverá organizar a forma e disposição dos blocos de informação ao longo das páginas da publicação, sem deixar de lado as imagens que venham a compor a obra e de acordo com a hierarquia da informação determinada.

A última fase do processo trata do aspecto macro da publicação, da forma como o conteúdo e os suportes visuais serão "empacotados" numa forma final. Neste momento são definidos o formato da publicação, o grid - ou grids - que soluciona os problemas visuais e organizacionais da publicação, a sequência entre as páginas, a cadência (ritmo visual) e o exterior da publicação (capa, contracapa).

A última seção do livro do autor apresenta estudos de caso de publicações que confirmam certa flexibilidade do processo criativo por meio 
dos relatos dos designers sobre suas experiências de trabalho. O trânsito e o retorno entre as fases existem, não prejudicam a qualidade do trabalho final e permitem alcançar melhores resultados por meio da reflexão e correção de certas inconsistências (Figura 2).

Figura 2 - Processo de design de Samara (2011).

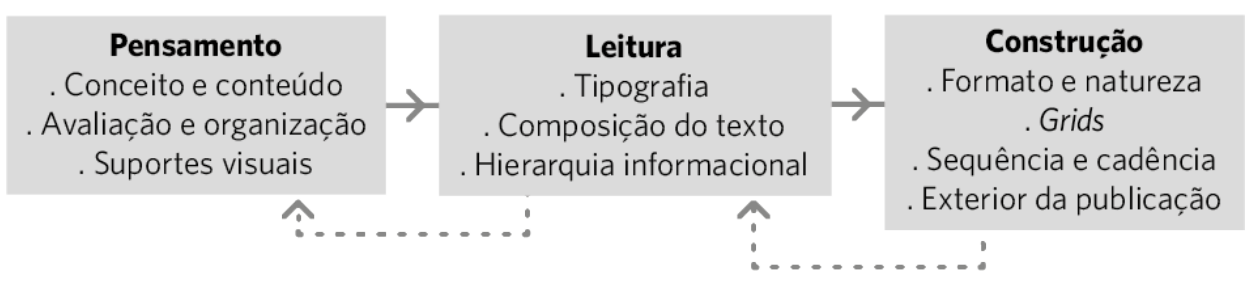

Fonte: os autores, baseados em Samara (2011).

\subsection{Processo Projetual de Dabner (2014)}

Dabner (2014) divide a obra em duas partes, "Princípios" e "Prática", e cada uma é dividida em unidades (que são encerradas por atividades práticas). A primeira parte disserta sobre as habilidades de pesquisa e o processo criativo em design, juntamente com princípios e fundamentos visuais que formam a base teórica necessária ao designer. "A linguagem do design é visual" e para ser utilizada é preciso que o designer tenha "consciência altamente desenvolvida de relações visuais, proporção, percepções dos princípios visuais e do mundo moderno, com seus complexos eventos e práticas" (DABNER, 2014, p. 8).

A primeira unidade da seção "Princípios", intitulada "Pesquisa e Conceitos", merece destaque. $\mathrm{O}$ autor considera que para ser interessante é preciso estar interessado. "Para serem bem-sucedidos, os designers precisam ser pesquisadores contumazes, com curiosidade natural" (DABNER, 2014, p. 10). O designer precisa ser um observador constante para criar repertório, não apenas pesquisando e vivenciando o mundo do design, mas também lendo os acontecimentos em diversas fontes, lendo livros de diferentes gêneros, estando aberto a novas experiências, compartilhando ideias e ouvindo pessoas. Este exercício constante poderá ser colecionado na forma de escritos, esboços, desenhos que formarão um "catálogo de inspirações" e ajudarão o designer a desenvolver sua "voz visual".

Além das noções básicas de pesquisa já mencionadas, o autor também descreve as abordagens do raciocínio linear e pensamento lateral; a prática do desenho exploratório; teorias de imagens e texto; pesquisa de públicos e mercados; e até orientações para a construção do planejamento do projeto, cronogramas e organização geral.

As três unidades seguintes da obra abordam fundamentos de composição (noções de composição; forma e espaço; simetria e assimetria; 
princípios de layout; ritmo e contraste; tamanho e formato, identidade e sistemas expandidos, fotografia e ilustração), fundamentos de tipografia (tipografia e sentido; anatomia dos tipos; compreensão e seleção de fontes; espaçamento; legibilidade e visibilidade; ênfase e hierarquia tipográfica; fios/ caixas e ornamentos tipográficos; o texto como imagem) e fundamentos da cor (terminologias; legibilidade, contraste e harmonia; cores na emoção e na linguagem; cor como informação).

A segunda parte do livro, "Prática", apresenta as ferramentas e técnicas do design necessárias à prática profissional. Todo designer deve estar atento às exigências tecnológicas correntes e familiarizado com os padrões do mercado. Todavia, o designer não pode se esquecer de que ferramentas não geram ideias e executam projetos, mas sim habilidades conceituais, intelectuais e formais.

As duas primeiras unidades da segunda parte completam o processo de design de caráter impresso (Figura 3). Elas abordam ferramentas e tecnologias (noções de fotografia e aquisição/pesquisa de imagem; programas de editoração eletrônica, de edição e manipulação de imagens bitmap, de edição de imagens vetoriais e de animação), produção gráfica e apresentações (preparação de arquivos para impressão; preparação de apresentações para o cliente; tipos e acabamentos de papel; impressão em cores; mídias impressas; impressão digital; prova de cor e prova de impressão).

Figura 3 - Processo de design, com ênfase no aprendizado, de Dabner (2014).

\begin{tabular}{|c|c|}
\hline $\begin{array}{c}\text { Princípios } \\
\text {. Pesquisa e conceitos } \\
\text { Fundamentos de composição } \\
\text {. Fundamentos de tipografia } \\
\text {. Fundamentos de cor }\end{array}$ & $\begin{array}{c}\text { Prática } \\
\text {. Ferramentas e tecnologias } \\
\text {. Produção gráfica/ } \\
\text { Web e interatividade } \\
\text {. Apresentações }\end{array}$ \\
\hline
\end{tabular}

Fonte: os autores, baseados em Dabner (2014).

A terceira unidade da obra aborda conceitos e particularidades do processo de desenvolvimento de um projeto de web (Figura 4). Projetos de web e interativos costumam ser executados por uma equipe profissional multidisciplinar, apesar de alguns profissionais conseguirem executar todo o processo por conta própria. A complexidade destes projetos é altamente variável, no entanto a área está habituada a trabalhar com um planejamento estruturado em fases e etapas de forma clara e objetiva. 
Figura 4 - Processo de desenvolvimento de projetos para web de Dabner (2014).

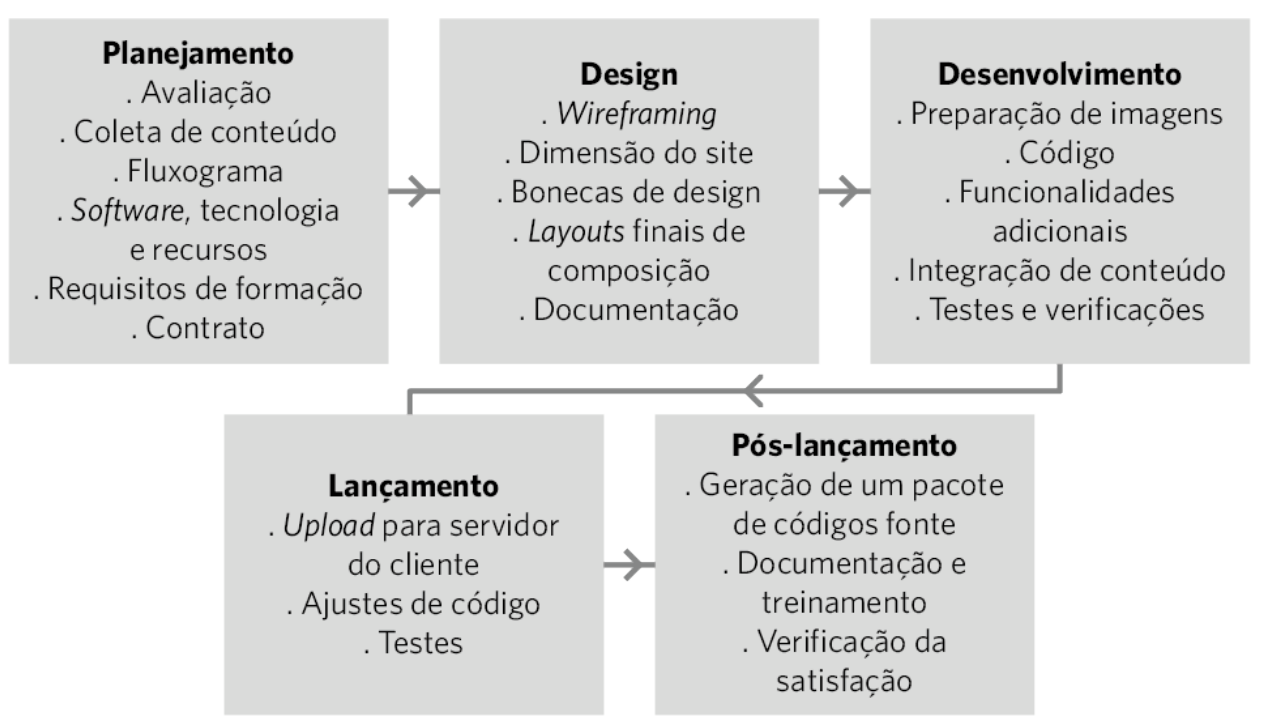

Fonte: os autores, baseadas em Dabner (2014).

A cultura de planejamento e de gestão de projetos é forte na área de tecnologia da informação e comunicação (TIC). O designer que entra em contato com o trabalho de web e interatividade tem ganhos expressivos de conhecimento sobre planejamento e gestão, uma experiência que pode ser facilmente aplicada no segmento impresso.

Apesar do caráter acadêmico do livro, o autor mescla ao conteúdo dicas profissionais para o estudante e futuro profissional. Por isso, é possível evoluir do processo de design voltado ao aprendizado acadêmico para outro voltado à prática profissional (Figura 5).

Figura 5 - Evolução do processo de design do aprendizado acadêmico à rotina profissional, de Dabner (2014).

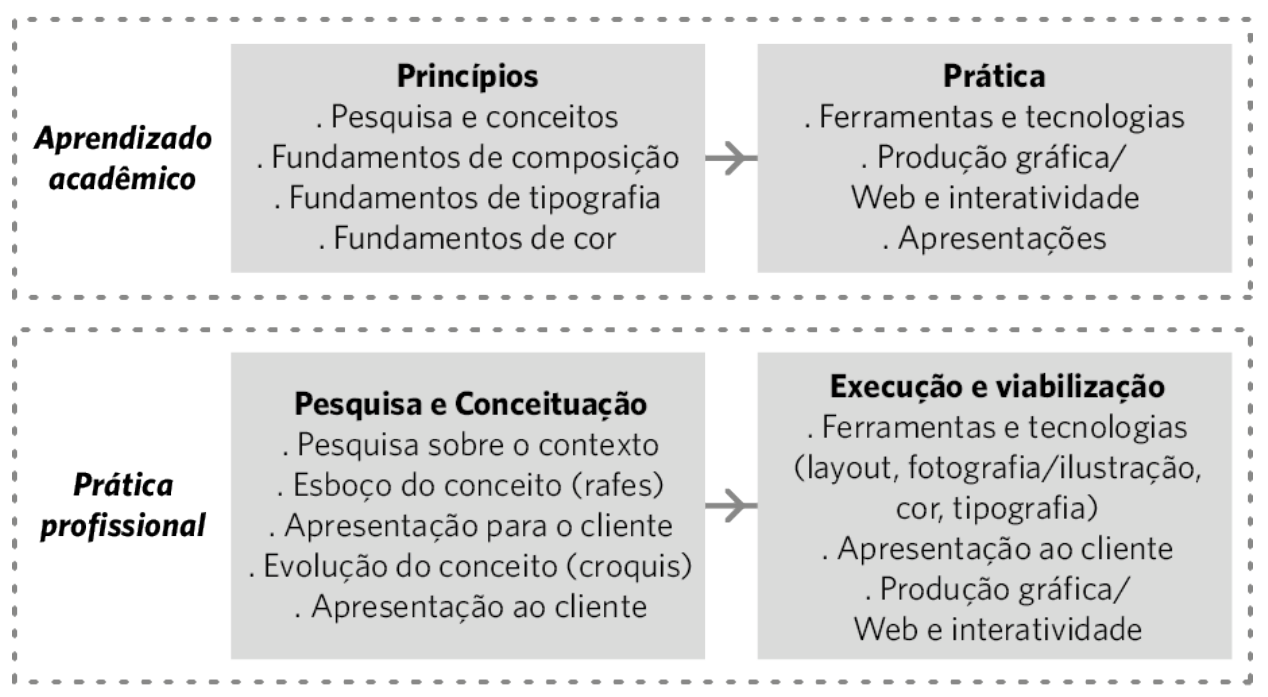

Fonte: os autores, baseados em Dabner (2014). 


\section{A REVISTA GALILEU}

A Galileu é uma revista mensal da Editora Globo. Foi criada em 1991 sob o nome de Globo Ciência e seu conteúdo abordava ciência e tecnologia. Em 1998, a revista foi renomeada como Galileu e ampliou sua abordagem para ciência, tecnologia e comportamento. Seu público se concentra na faixa etária entre 18 e 34 anos (GALILEU, 2014).

\subsection{Um Novo Projeto Gráfico}

Em setembro de 2015, a revista Galileu anunciou em seu site que iria estrear um novo projeto gráfico, realizar algumas mudanças em suas seções e formar um conselho - o 1 conselho Galileu -, que consistiria em um grupo de leitores para avaliar a revista, dar sugestões e participar das decisões da equipe editorial por seis meses em troca de acesso a conteúdo exclusivo e prêmios. A matéria convidou os leitores a se candidatarem às vinte vagas do conselho por meio de um formulário online (GALILEU, 2015).

Em novembro, a nova revista Galileu, edição 292, chegou às bancas: capa com layout mais minimalista e impressa em um papel de maior gramatura com textura fosca; nova identidade visual e tipografia que remetiam aos lambelambes urbanos; as seções tinham novo grid e um pôster como brinde. Além disso, seu slogan foi alterado para "A ciência ajuda você a mudar o mundo", pois a nova revista trouxe a proposta de abordar todo o tipo de ciência, seja ela exata, biológica ou social.

O novo projeto gráfico ganhou a medalha de prata na seleção da Society for News Design (SND) na categoria mudança de projeto gráfico, que seleciona anualmente os melhores trabalhos visuais em jornais e revistas do mundo todo (KIST; QUICK, 2016a). A revista também recebeu três méritos da Society of Publication Designers (SPD), importante premiação mundial para o mercado de revistas: edição completa, redesign de seção (Dossiê) e design de seção (Antimatéria) (KIST; QUICK, 2016b).

A matéria escolhida para a capa da edição 292 falou sobre identidade de gênero. Na seção "Primeiramente" - uma espécie de carta ao leitor - Gustavo Poloni, o diretor de redação da revista, descreve o processo de desenvolvimento do novo projeto que começou no mês de junho, unindo redação, direção de arte e designers. Rafael Quick, editor de arte, teve importante papel na evolução do projeto. Poloni (2015) menciona que uma pergunta de Quick levou à reflexão sobre qual caminho seguir: "o que só o analógico pode fazer?". Ele se referia às possibilidades da mídia impressa diante das tecnologias e suportes digitais. Poloni (2015, p. 4) argumenta que a reflexão fez com que a equipe compreendesse que a função da revista impressa era explorar e valorizar o que

Projética, Londrina, v.10, n.3, p. 9-26, jul./dez. 2019 
o jornalismo de internet não pode fazer: "valorizar as fotos, os infográficos, usar suas páginas para surpreender o leitor. Ou seja, precisa valorizar o papel". Em meio às discussões sobre a missão da revista, Quick começou a rabiscar o projeto gráfico. A equipe saiu em busca de referências.

Dos lambe-lambes tão em moda nas grandes cidades emprestamos a tipografia. Dos atlas e livros, as texturas e o cuidado nos detalhes. E nos inspirando nas revistas que amamos (sim, aqui amamos revistas!), criamos uma capa mais limpa, seções modernas, a pegada agressiva das reportagens (POLONI, 2015, p. 4).

Quadro 1 - Síntese do novo projeto gráfico da revista Galileu.

\begin{tabular}{|c|c|c|c|}
\hline 1. Linha Editorial & 2. Projeto gráfico & 3. Novas seções & 4. Conselho \\
\hline $\begin{array}{l}\text { "Foi uma coisa que } \\
\text { mudou muito pouco } \\
\text { na nova Galileu. } \\
\text { Continuamos sendo } \\
\text { a revista que usa a } \\
\text { ciência como ponto } \\
\text { de partida para } \\
\text { explicar o mundo. } \\
\text { Com uma diferença: } \\
\text { queremos entrar } \\
\text { mais a fundo } \\
\text { em assuntos } \\
\text { espinhosos, como } \\
\text { transexualidade". }\end{array}$ & $\begin{array}{l}\text { "Se não reparou, } \\
\text { vale a pena voltar } \\
\text { à capa para ver } \\
\text { o novo logo. Não } \\
\text { é só: a revista } \\
\text { também tem fonte } \\
\text { de lambe-lambe, } \\
\text { uma seção com } \\
\text { identidade visual } \\
\text { bem marcada, uma } \\
\text { paleta de cores } \\
\text { do início ao fim, } \\
\text { matérias com abres } \\
\text { mais forte, etc". }\end{array}$ & $\begin{array}{l}\text { "A Galileu passou } \\
\text { por uma grande } \\
\text { reorganização. A } \\
\text { seção que abre a } \\
\text { revista tornou-se } \\
\text { o Antimatéria. } \\
\text { Além das notas } \\
\text { mais quentes sobre } \\
\text { ciência, tecnologia } \\
\text { e comportamento, } \\
\text { ele engloba a seção } \\
\text { de cultura. O Dossiê } \\
\text { (mais moderno) } \\
\text { é seguido pelas } \\
\text { reportagens. A } \\
\text { revista acaba com } \\
\text { o Panorâmica, o } \\
\text { Ultimato e o Só + } 1 \\
\text { Minuto". }\end{array}$ & $\begin{array}{l}\text { "A partir desta } \\
\text { edição, Galileu } \\
\text { conta com um } \\
\text { grupo de leitores } \\
\text { que vai avaliar suas } \\
\text { edições, sugerir } \\
\text { ideias para a } \\
\text { marca e participar } \\
\text { da criação de } \\
\text { pautas. Em troca, } \\
\text { terão acesso } \\
\text { a informações } \\
\text { exclusivas e } \\
\text { ganharão prêmios". }\end{array}$ \\
\hline
\end{tabular}

Fonte: adaptado de Poloni (2015, p. 4).

As edições seguintes mantiveram a temática contemporânea: indústria alimentícia e desequilíbrio ambiental; crise política, ambiental e econômica; cultura da violência; indústria do fast fashion; mídias sociais e ciberativismo; fé versus saúde; sexualização da infância e adolescência; meritocracia e desigualdade; e a atuação da polícia militar brasileira. A seguir, é possível visualizar as capas das dez primeiras edições da revista desde o redesign do projeto gráfico (Figura 6). 
Figura 6 - Capas das edições 292 a 301 da Revista Galileu.
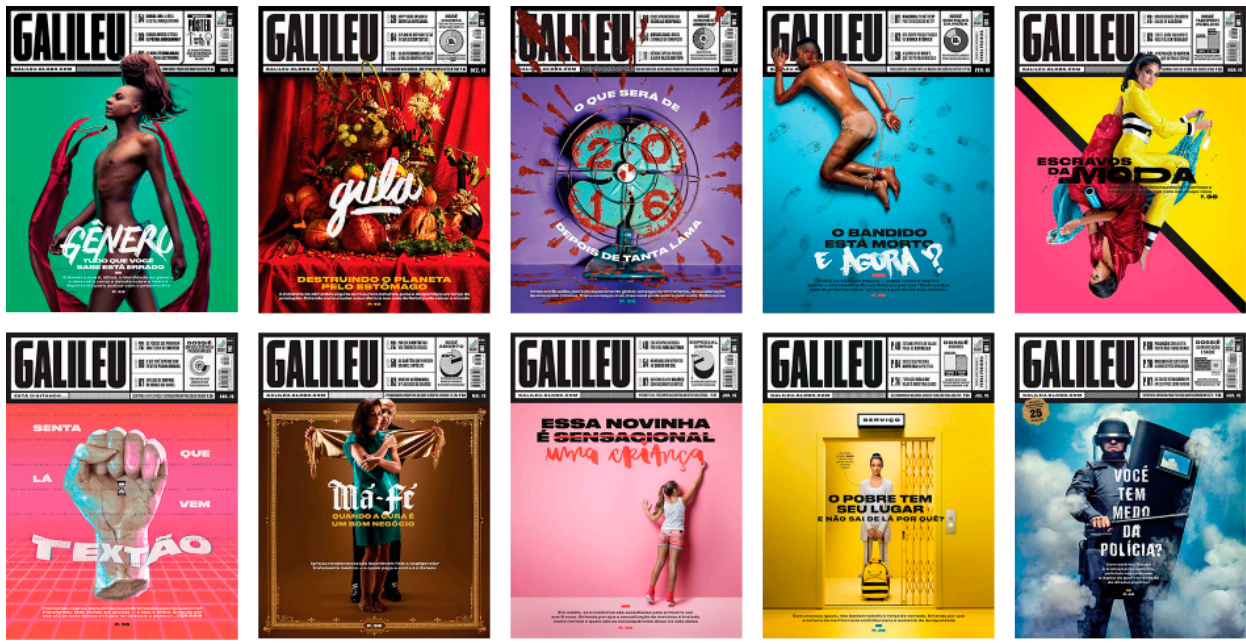

Fonte: Galileu ([2016a?]).

Parte do projeto gráfico pode ser visualizada na figura abaixo. A paleta de cores de matéria de capa percorre toda a revista. As matérias são ilustradas com diversas técnicas e a mistura entre elas, tais como fotografia, manipulação digital, ilustração, dobradura e recorte em papel - que recebem destaque dentro da revista (Figura 7).

Figura 7 - Páginas internas da Galileu.
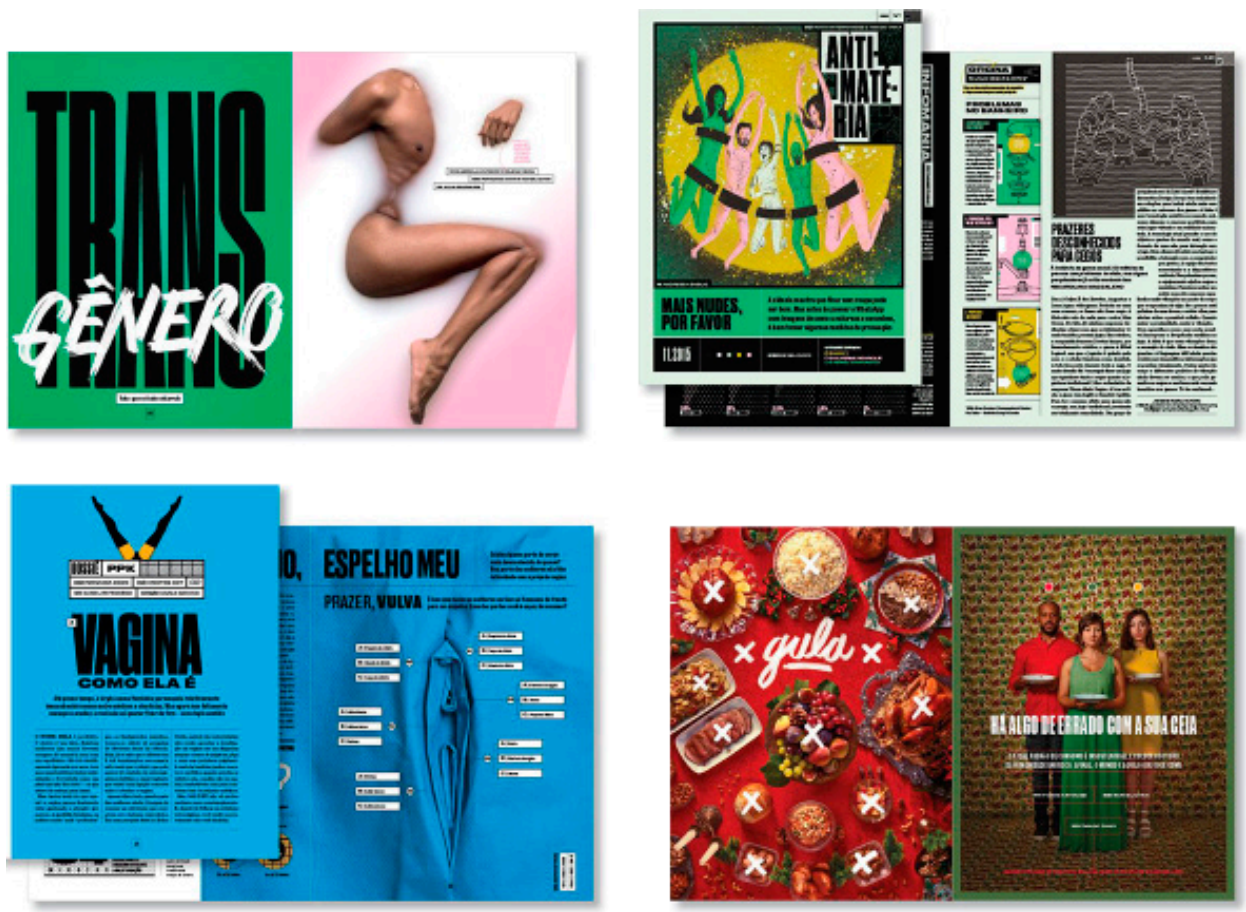

Fonte: Galileu ([2016b?]).

O pôster foi brinde da revista por seis edições e apresentou diferentes temas: a história da energia (patrocinado pela Petrobrás), a saga Star Wars, o calendário astronômico de 2016, a sazonalidade de frutas, legumes, verduras e 
outros alimentos, destinos alternativos de viagem no Brasil e um guia de raças caninas e suas origens (Figura 8).

Figura 8 - Pôsteres da Galileu das edições 292 a 297.
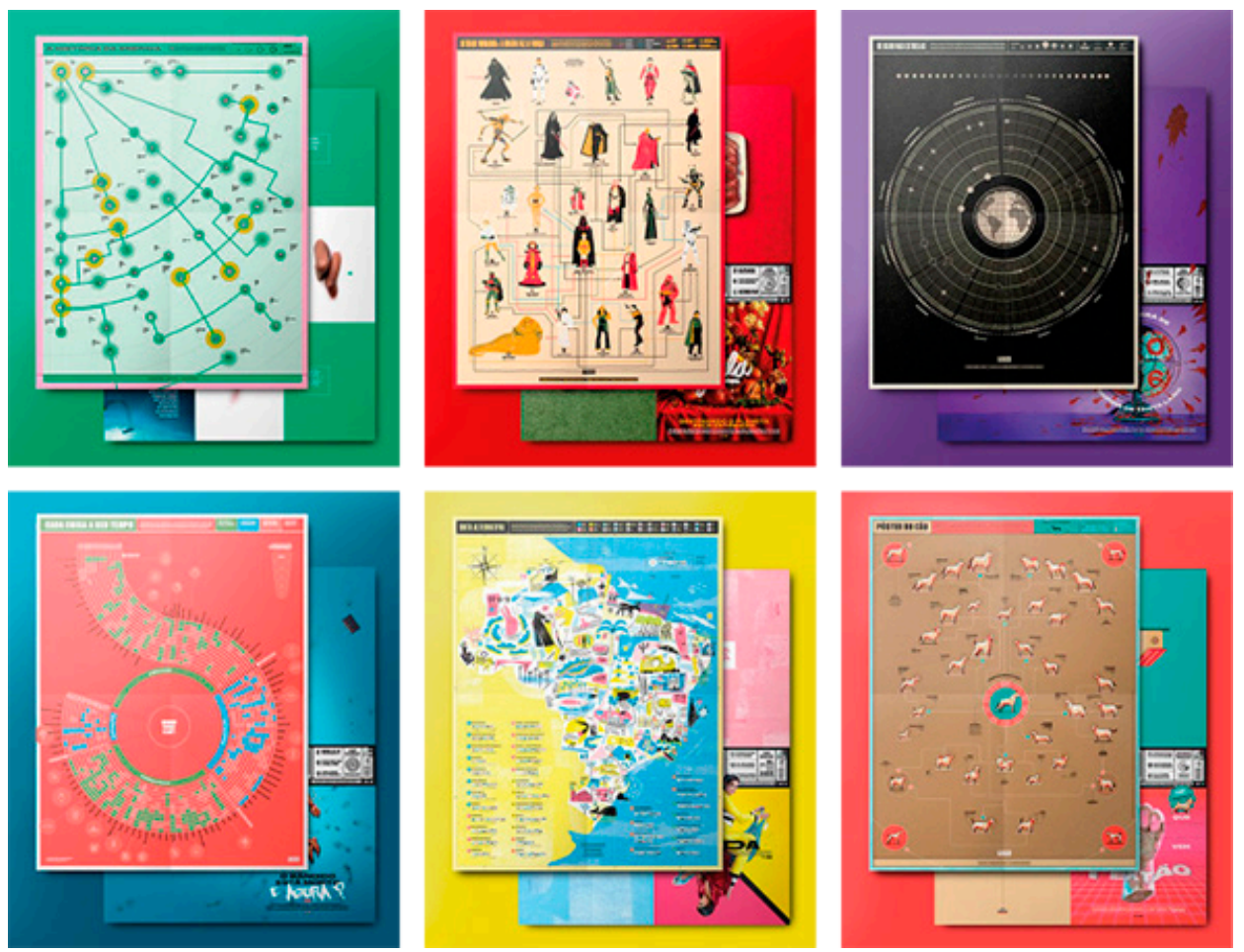

Fonte: Galileu ([2016c?]).

\subsection{Processo Colaborativo: Conselho Editorial de Leitores}

A edição 292 apresentou o resultado da escolha do 10 conselho de leitores citado por Poloni (2015). Dentre 307 inscritos (o mais novo de 11 anos de idade e o mais velho de 77 anos), foram escolhidos 20 leitores, sua maioria entre 21 e 30 anos e moradores da região Sudeste. A seção ainda expôs algumas das respostas dos inscritos no formulário de inscrição: estado de residência, filmes e livros favoritos e a coisa mais legal que já fizeram na vida. O conselho de leitores interage com a equipe da revista por meio de um grupo fechado e exclusivo no Facebook.

O 1ํ conselho atuou na avaliação e debate sobre as edições 292 a 299. As opiniões sobre o conteúdo são publicadas na edição posterior àquela avaliada. Estas informações são exibidas de forma quantitativa - com uso de gráficos de percentual para demonstrar diferentes opiniões e médias aritméticas atribuídas a determinadas matérias - e qualitativa - transcrevendo opiniões e pontos de vista relevantes para a análise crítica da edição. Todo o conteúdo é apresentado em uma linguagem descontraída, típica do público leitor e da revista. 
No final do mês de abril de 2016, a revista abriu inscrições online para a segunda temporada do conselho de leitores (FERNANDES, 2016b). A edição de junho de 2016 divulgou os 19 novos conselheiros (dentre 258 inscritos) e informou que a próxima temporada do conselho aconteceria em janeiro de 2017 (FERNANDES, 2016a). A segunda temporada do conselho estreou avaliando a edição 300 na seção "Conselho" da edição 301.

\section{ANÁLISE DO PROCESSO PROJETUAL}

Diante de toda a descrição do processo de desenvolvimento do projeto gráfico e editorial, é possível esboçar as fases e atividades deste trabalho, tendo como base os processos de design anteriormente apresentados - Fuentes (2006), Samara (2011) e Dabner (2014) (Figura 9).

Figura 9 - Processo projetual de redesign da Revista Galileu.

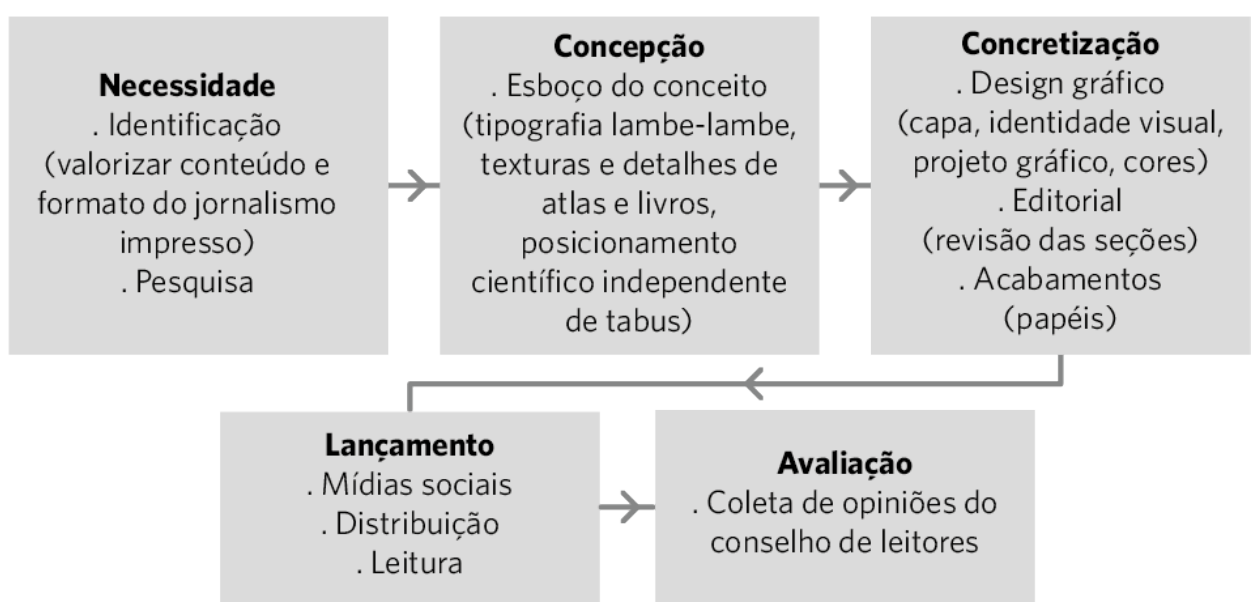

Fonte: os autores.

O processo de redesign da revista pode ser dividido em cinco fases: necessidade, onde o cenário foi estudado e os novos rumos da revista começaram a ser delineados; concepção, onde o conceito começou a ser expresso de forma tangível; concretização, fase prática de refinamento do conceito estabelecido e materialização do produto; lançamento, fase de divulgação nas redes sociais, distribuição nas bancas e leitura por parte do público; e, por fim, a avaliação pelo conselho de leitores selecionado.

Seguindo as mesmas referências, é possível esboçar o processo projetual utilizado para todas as edições a partir do redesign do projeto gráfico (Figura 10). 
Figura 10 - Processo projetual contínuo da Revista Galileu.

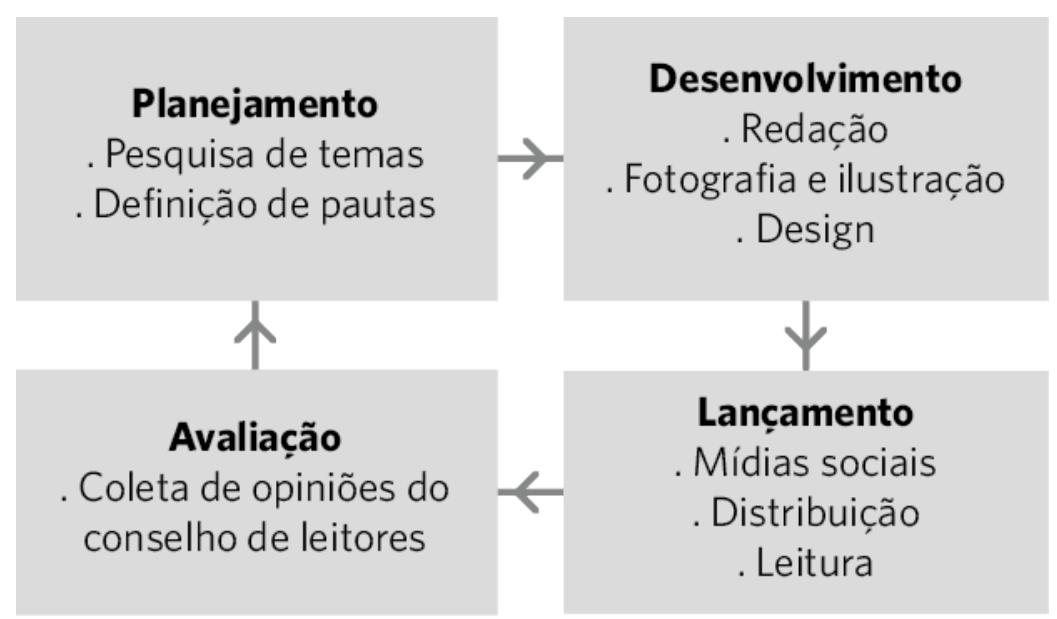

Fonte: os autores.

A primeira fase é de planejamento, onde temas interessantes ao escopo da revista são identificados e pautas são definidas. A segunda fase é a de desenvolvimento - redação, fotografia, ilustração e design da revista -, que consiste na materialização do que foi definido no planejamento. A terceira e quarta fase se assemelham às fases de lançamento e avaliação identificadas no processo de redesign (Figura 9); aqui se pode destacar que o conselho de leitores se consolidou como método dentro da revista e é responsável por realimentar o processo projetual de cada edição, tornando-o cíclico e contínuo.

\section{CONSIDERAC̣õES FINAIS}

Fuentes (2006), Samara (2011) e Dabner (2014) conseguem aliar fundamentos visuais com processos de design gráfico e editorial e podem ser considerados referências em ensino e prática do design gráfico e editorial.

Na contramão do fechamento de várias revistas, a Galileu optou por uma mudança a fim de valorizar o jornalismo impresso. A equipe da revista é multidisciplinar - jornalistas, designers, estagiários em texto e design e colaboradores externos, como fotógrafos e ilustradores. No entanto, o processo percorrido para o desenvolvimento do novo projeto pode ser caracterizado como interdisciplinar, pelo diálogo, interação e discussão promovidos, incluindo até o público leitor.

O novo projeto gráfico e, de certa forma, editorial é consistente e representa o posicionamento contemporâneo do produto. Explorar temas oriundos das ciências sociais, polêmicos e que não são considerados como "ciência tradicional" por parte da massa leitora, é um passo importante na desmistificação de tabus, preconceitos e na disseminação da informação. 
O lançamento e manutenção de um conselho de leitores pode ser considerado um método de diferenciação importante que coloca o leitor como ator indispensável para o processo projetual. É a execução do conselho de Dabner (2014, p. 11): "ouça as pessoas".

Desta forma, o novo projeto da revista Galileu pode ser considerado um exemplo de trabalho contemporâneo que reúne design, comunicação e artes visuais na materialização de um produto que discute a ciência em toda sua amplitude a fim de informar da melhor forma seu leitor.

\section{Agradecimentos}

Os autores agradecem à Coordenação de Aperfeiçoamento de Pessoal de Nível Superior - CAPES pela bolsa de mestrado demanda social.

\section{REFERÊNCIAS}

BONSIEPE, Gui. Design como prática de projeto. São Paulo: Blucher, 2012.

BONSIEPE, Gui. Design, cultura e sociedade. São Paulo: Blücher, 2011.

BÜRDEK, Bernhard E. Design: história, teoria e prática do design de produtos. São Paulo: Blücher, 2006.

DABNER, David. Curso de design gráfico: princípios e práticas. São Paulo: Gustavo Gili, 2014.

FERNANDES, Nathan. Conselho. Galileu, São Paulo, ed. 299, p. 6, jun. $2016 a$.

FERNANDES, Nathan. Faça parte do Conselho GALILEU. Galileu, São Paulo, 19 maio 2016b. Disponível em: http://revistagalileu.globo.com/Revista/ noticia/2016/04/faca-parte-do-conselho-galileu.html. Acesso em: 19 ago. 2016.

FUENTES, Rodolfo. A prática do design gráfico: uma metodologia criativa. São Paulo: Edições Rosari, 2006.

GALILEU. Capas. São Paulo, [2016a?]. Pinterest: revistagalileu. Disponível em: https://br.pinterest.com/revistagalileu/capas/. Acesso em: 18 ago. 2016.

GALILEU. Faça parte do 1ํ Conselho GALILEU. Galileu, São Paulo, 23 set. 2015. Disponível em: http://revistagalileu.globo.com/Sociedade/Comportamento/ noticia/2015/09/faca-parte-do-1-conselho-galileu.html. Acesso em: 15 out. 2015.

GALILEU. Fotos da linha do tempo. São Paulo, [2016b?]. Facebook: revistagalileu. Disponível em: https://www.facebook.com/revistagalileu/ photos/?tab=album\&album_id=102109376648. Acesso em: 18 ago. 2016. 
GALILEU. Galileu Midiakit 2014. São Paulo, 2014. 24 slides. Disponível em: http://galileu.globo.com/midiakit/arquivos/MidiaKit_Galileu_2014.pdf. Acesso em: 18 ago. 2016.

GALILEU. Posters. São Paulo, [2016c?]. Pinterest: revistagalileu. Disponível em: https://br.pinterest.com/revistagalileu/posters/. Acesso em: 18 ago. 2016.

GOMEZ, Luiz Salomão Ribas. Os 4P's do design: uma proposta metodológica não linear de projeto. 2004. 142 f. Tese (Doutorado em Engenharia da Produção) - Universidade Federal de Santa Catarina, Florianópolis, 2004.

KIST, Cristine; QUICK, Rafael. Primeiramente. Galileu, São Paulo, ed. 296, p. 4, mar. 2016a.

KIST, Cristine; QUICK, Rafael. Primeiramente. Galileu, São Paulo, ed. 297, p. 4, abr. 2016b.

KRUCKEN, Lia. Design e território: valorização de identidades e produtos locais. São Paulo: Studio Nobel, 2009.

MORAES, Dijon de. Design e complexidade. In: MORAES, Dijon de; KRUCKEN, Lia (org.). Cadernos de estudos avançados em design: transversalidade. Belo Horizonte: UEMG, 2008. Caderno 2, v. 1, p. 7-22.

MOURA, Mônica. Interdisciplinaridades no design contemporâneo. In: MENEZES, Marizilda; PASCHOARELLI, Luis Carlos; MOURA, Mônica (org.). Metodologias em design: inter-relações. São Paulo: Estação das Letras e Cores, 2011. p. 274-290.

PLUNKETT, John. O mundo conectado. In: HELLER, Steve; PETTIT, Elinor. Design em diálogo: 24 entrevistas por Steven Heller e Elinor Pettit. São Paulo: Cosac Naify, 2013. p. 306-316.

POLONI, Gustavo. Primeiramente: em constante transformação. Galileu, São Paulo, ed. 292, p. 4, nov. 2015.

PORTUGAL, Cristina. Design, educação e tecnologia. Rio de Janeiro: Rio Books, 2013.

REYES, Paulo. Processo de projeto em design: uma proposição crítica. In: MENEZES, Marizilda; PASCHOARELLI, Luis Carlos; MOURA, Mônica (org.). Metodologias em design: inter-relações. São Paulo: Estação das Letras e Cores, 2011. p. 375-391.

SAMARA, Timothy. Guia de design editorial: manual prático para o design de publicações. Porto Alegre: Bookman, 2011.

VAN DER LINDEN, Júlio Carlos de Souza; LACERDA, André Pedroso de. Metodologia projetual em tempos de complexidade. In: MARTINS, Rosane Fonseca de Freitas; VAN DER LINDEN, Júlio Carlos de Souza (org.). Pelos caminhos do design: metodologia de projeto. Londrina: Eduel, 2012. p. 83-150. 